\title{
CONSUELO GARCÍA GALLARÍN (DIR) Y KARLOS CIB ABASOLO (COORD.) (2009): LOS NOMBRES DE PERSONA EN LA SOCIEDAD Y EN LA LITERATURA DE TRES CULTURAS. MADRID, SILEX, 195 PÁGS.
}

\author{
MARÍA SimÓn PARRA \\ Universidad de Alcalá \\ maria.simon@uah.es
}

Los nombres de persona en la sociedad y en la literatura de tres culturas es una obra que ha visto la luz recientemente. Los estudios que constituyen el volumen pertenecen a profesores de la Universidad Complutense de Madrid que han trabajo en varias ocasiones en el campo de la onomástica y concretamente en el de la antroponimia.

Las primeras páginas de la obra ofrecen una breve visión sobre el nombre propio de persona y la influencia que sobre este puede ejercer la sociedad del momento. Además presenta el tema común de los diferentes estudios de la obra que es "la importancia de los nombres de persona en todas las culturas y los mecanismos internos de cada una de ellas en virtud de los cuales los antropónimos van y vienen, entran en una cultura, se instalan y, en determinado momento, desaparecen"(pág. 9).

El libro está constituido por un total de seis trabajos que abarcan el tema de la antroponimia tanto en el ámbito literario como lingüístico. El primer capítulo de la monografía pertenece a Cid Abasolo y su artículo "Antroponimia en la literatura vasca contemporánea: Anjel Lertxundi". En él, Cid Abasolo se centra en el estudio de la antroponimia en la literatura vasca. Para ello toma como objeto de estudio las obras de Anjel Lertxundi y llama la atención sobre la importancia que tiene para los escritores elegir adecuadamente los nombres de los personajes de sus obras. Los nombres de pila en las obras literarias tienen una doble función, por un lado, identificar a los personajes y por otro, caracterizar a los mismos. Con el estudio de las obras de Lertxundi, Cid Abasolo también muestra la influencia que la sociedad vasca puede tener en el terreno de la antroponimia, ya que las diversas tradiciones 
antroponímicas vascas han tenido una gran influencia en la literatura vasca tanto en los autores de las obras como en los personajes de las mismas.

En el segundo trabajo titulado, "Una fuente histórico-documental para los estudios de onomástica: la carta de vecindad", Juan Carlos Galende Díaz presenta las cartas de vecindad como fuente de información de datos antroponímicos ya que la finalidad de las mismas es la recopilación de la identificación de los ciudadanos de un lugar. Además ofrece la evolución que los censos han experimentado a lo largo de la historia desde el siglo XVI, concretamente desde el año 1528, fecha en la que aparece el primer censo importante, hasta la actualidad. Como señala Galende Díaz "las cartas de vecindad, documentalmente, evolucionan desde un punto de vista material y formal, tanto en el tiempo como en el espacio, es decir, cronológica y geográficamente, aunque bien es verdad que siempre mantienen unas singularidades básicas" (pág. 58). La estructura básica que presentan este tipo documental es: protocolo, cuerpo y escatocolo. Ofrece también los requisitos que los habitantes de un lugar deben cumplir para poder inscribirse en estos censos y los privilegios que esto proporcionaba a los vecinos. Entre los privilegios tenemos, por ejemplo, el trato preferente que los vecinos que estaban apuntados al censo tenían en los viajes, la exención de ciertos tributos, etc.

El tercer trabajo de la obra "Variación y cambio antroponímicos: los nombres de persona en el periodo clásico" corresponde a la profesora García Gallarín. En las primeras páginas del estudio esta profesora presenta el objetivo de su trabajo, "hemos pretendido realizar un estudio sobre aspectos poco explorados de la historia de los nombres de pila; además de los problemas etimológicos que plantean, hemos intentado precisar cuáles son los factores que han contribuido a reducir la variación de dicha subclase onomástica, tan expuesta a presiones lingüísticas y extralingüísticas" (pág. 71). García Gallarín, en este trabajo, muestra cómo la variación antroponímica se reduce en el paso del periodo medieval al clásico. Además realiza un estudio de los factores internos (préstamos, cambios de frecuencia, pérdida o adición de variantes de un nombre tradicional, etc.) y externos (contactos de lengua, corrientes socioculturales, etc.) que influyen en el cambio antroponímico. Como factores internos señala el desarrollo de los diminutivos (Juanico, Juanillo, Inesica, etc.), la aparición de hipocorísticos (Bela, Mari, etc.) el triunfo de los nombres dobles (Juan Francisco, Ana María, Juan Manuel, María Clara) y la popularización de ciertas fórmulas designativas favorecieron la desaparición de antiguas fórmulas identificativas (Juanico o Juanillo sustituyeron a la estructura Juan el moço, que era un estructura muy habitual en la documentación medieval); y como factores externos destaca el prolongado 
contacto del español con otras lenguas, el fin de una sociedad multicultural, la expansión del castellano por las conquistas, la fuerza del Humanismo, las reformas de la Iglesia, etc.

El estudio "El cambio antroponímico en la Inglaterra medieval: desde las invasiones germánicas al inglés medio de Geoffrey Chaucer” de Maíz Arévalo, constituyen el cuarto trabajo de la obra que se centra en el estudio antroponímico de la lengua inglesa de la Edad Media. El trabajo está dividido en dos partes bien diferenciadas. Por un lado, estudia la influencia que tienen las cambios histórico-sociales en la antroponimia del momento como por ejemplo la progresiva desaparición de los nombres anglosajones y la fijación de los nombres que introducían los nuevos pobladores normados; el empleo de nombres bíblicos con la llegada del Cristianismo, etc. Por otro, analiza las variaciones formales y gráficas que muestran los nombres de pila ingleses de la Edad Media como por ejemplo la formación de hipocorísticos a partir de la apócope, variantes derivadas de apellidos que se pueden emplear como nombres de pila y como apellidos, etc. Además del estudio de los factores externos e internos que influyen en el cambio antroponímico, para el estudio de la antroponimia de finales del siglo XIV se centra en el análisis de algunas obras de Geoffrey Chaucer lo que le permite comprobar que en muchas ocasiones en la elección de los nombres tiene una gran influencia la sociedad del momento. Maíz Arévalo cierra el trabajo con un breve estudio en el que ofrece los cambios lingüísticos que se han ido produciendo en cuatro nombres de pila (Robert, William, Matilda y Alice) que ella ha seleccionado.

El quinto trabajo de la monografía es el de Bravo Llatas, titulado "Variación y cambio antroponímicos: Isabel, Elizabeth, Elisabeth". En este trabajo, Bravo Llatas presenta un estudio estadístico del nombre de pila Isabel, que predomina en España y Elisabeth, que lo hace en Hispanoamérica. Los resultados obtenidos de dicho estudio revelan además las diferentes tendencias antroponímicas que se dan entre España e Hispanoamérica. Por otro lado, el estudio de la variación y cambios antroponímicos de ambos nombres muestra variaciones gráficas (Sabela, Elisabetta), variaciones hipocorísticas (Bel, Elisa), formación de nombres compuestos y acrónicos de los mismos (Maribel, Idaliza). La aportación de los diferentes gráficos que ha elaborado Bravo Llatas para su estudio, permiten seguir con mayor facilidad la cantidad de datos estadísticos que ofrece la autora del trabajo, además de quedar más clara la diferencia entre las dos zonas de estudio, España e Hispanoamérica.

Cierra la monografía el trabajo de Navas Sánchez, titulado "El nombre propio de persona como marca social en la obra de Gil Vicente". Navas Sánchez realiza un estudio desde un punto de vista multicultural de la antro- 
ponimia que aparece en la obra del escritor portugués. Comienza su trabajo señalando que "no existe una bibliografía de referencia, que sepamos, por lo menos en portugués, en lo que respecta a la equiparación del nombre propio con las funciones subjetivas que su designación ejerce sobre los personajes de la obra literaria, aunque es evidente que los autores recurren a ese saber para caracterizar a sus actores" (pág.171). En su estudio ofrece un análisis de los nombres que caracterizan a los personajes de las obras de Gil Vicente, marcando que en muchos ocasiones toma como fuente las obras de los escritores españoles del momento. Por ejemplo Gil es el nombre de pila de uno de los pastores de las obras del autor portugués y este nombre ya había sido empleado por Lucas Fernández y Juan del Encina; algunos nombres de personajes nobles e hidalgos se llaman Amadís de Gaula, como en la novela del mismo nombre, etc. Además ofrece un anejo al final del mismo constituido por los nombres de pila masculinos y femeninos de las obras del escritor portugués. Navas Sánchez señala que es "un cuadro en el que cotejamos la relación entre nombre y oficio o profesiones, sexos o categorías sociales de los personas para, por un lado, constatar su interrelación, si existe, y, por otro, verificar la tradición antroponímica literaria que tales nombres pueden aportar" (pág. 173).

El apartado de conclusiones que se añade al final de cada estudio permite que las ideas generales de cada uno de ellos queden mucho mejor asentadas. El trabajo que han elaborado estos seis profesores es una valiosa aportación al mundo de la onomástica y concretamente al de la antroponimia. Todos los estudios que constituyen la obra resultan muy útiles a los investigadores de esta materia, pues aportan ideas muy interesantes tanto desde el punto de vista literario como lingüístico. Además consideramos que ha sido una idea brillante que los trabajos de estos seis grandes investigadores hayan sido recogidos en un mismo volumen y que este haya sido publicado. 